\title{
PERANCANGAN DAN IMPLEMENTASI SISTEM INFORMASI PEMASANGAN BARU LISTRIK BERBASIS WEB BARCODE
}

\author{
Andri Suryadi \\ Program Studi Teknologi Informasi Institut Pendidikan \\ suryadi.andri@yahoo.com
}

\begin{abstract}
The new electrical installation information system is an information system that has been computerized by the system. in a new electrical installation system the admin enters the data of the applicant who wants to pair the new electricity in his home automatically to the database and makes it easy for the admin to search for data in the future. If the system is not computerized and only manually, the applicant's data will still be stacked in a file cabinet, so that when making the report it has difficulty in searching the applicant's data and has the risk of losing data. This is because it is not supported by the presence of storage media in the form of a database system for management of applicant data. Based on this, the new web barcode-based electrical installation information system can help the applicant in registering the electricity installation and become a system of information delivery that can provide convenience in processing the applicant's data for administrative staff, especially in processing and data storage applicant data.
\end{abstract}

Keywords - Systems, Information, Installation of new electricity

\begin{abstract}
Abstrak - Sistem informasi pemasangan listrik baru merupakan sistem informasi yang tsudah terkomputerisasi sistemnya . dalam sebuah sistem pemasangan listrik baru admin menginputkan data pemohon yang ingin memasangkan listrik baru dirumahnya secara otomatis ke database dan memudahkan admin dalam pencarian data dikemudian hari . Jika sistem nya belum terkomputerisasi dan hanya manual saja nantinya data pemohon masih ditumpuk dalam lemari arsip, sehingga pada saat pembuatan laporan memiliki kesulitan dalam pencarian data pemohon dan memiliki resiko kehilangan data. Hal ini karena tidak didukung dengan adanya media penyimpanan berupa sistem database untuk manajemen data pemohon. Berdasarkan hal tersebut maka dengan sistem informasi pemasangan listrik baru berbasis web barcode , ternyata dapat membantu pemohon dalam mendaftar pemasangan listrik dan menjadi sistem penyampaian informasi yang dapat memberikan kemudahan dalam hal pengolahan data pemohon bagi pegawai bagian administrasi pada khususnya dalam melakukan pengolahan dan juga penyimpanan data-data pemohon.
\end{abstract}

Kata Kunci : Sistem, Informasi, Pemasangan baru listrik

\section{PENDAHULUAN}

PT PLN Rahayu Cipta jaya merupakan perusahaan yang bergerak dibidang jasa konstruksi umum, penyedia jasa pelayanan teknik dan listrik serta pengadaan barang dan jasa konstruksi listrik. Namun dalam prosesnya pada kantor tidak menggunakan komputer sebagai alat bantu dalam proses kelancaran suatu pekerjaan saat pengolahan data. Proses pendaftaran pemasangan listrik baru pada masih menggunakan cara dimana pemohon datang langsung kekantor untuk menyerahkan berkas persyaratan pemasangan listrik baru, kemudian pemohon harus mengisi formulir pemasangan listrik yang telah disediakan oleh PLN. Hal ini dapat menyebabkan antrian panjang pemohon dan proses pendaftaran pemasangan listrik baru 
berjalan lambat. Selain itu data pemohon masih ditumpuk dalam lemari arsip, sehingga pada saat pembuatan laporan memiliki kesulitan dalam pencarian data pemohon dan memiliki resiko kehilangan data. Hal ini karena tidak didukung dengan media penyimpanan berupa sistem database untuk manajemen data pemohon. Oleh karena itu, berdasarkan uraian diatas penulis tertarik untuk merancang suatu sistem yaitu "Sistem Informasi Pemasangan Listrik Baru Berbasis Barcode", agar aplikasi ini dapat membantu kinerja PLN dalam upaya meningkatkan pelayanan terhadap pelanggan.

\section{Kajian Teoritis}

\section{A. Sistem}

Menurut Jogiyanto (2005:1), "Sistem adalah suatu jaringan kerja dari prosedurprosedur yang saling berhubungan, berkumpul bersama-sama untuk melakukan suatu kegiatan atau untuk menyelesaikan suatu sasaran yang tertentu"

\section{B. Informasi}

Menurut Jogiyanto (2005:8), "Informasi adalah data yang telah diolah menjadi bentuk yang lebih berarti dan berguna bagi penerimanya untuk mengambil keputusan masa kini maupun masa yang akan datang".

\section{UML (Unified Modeling Language)}

Menurut Rosa dan Shalahuddin (2013:133), "UML adalah salah satu satu standar bahasa yang banyak digunakan di dunia industry untuk mendefinisikan requiretment, membuat analisis dan desain, serta menggambarkan arsitektur dalam pemrograman berorientasi objek"

\section{Metode Pengembangan Sistem}

Menurut Pressman (2012:50), dalam melakukan perancangan sistem yang akan dikembangkan dapat menggunakan metode prototype. Metode ini dimulai dengan pengumpulan kebutuhan, kemudian membuat rancangan kilat yang selanjutnya akan dievaluasi kembali sebelum diproduksi secara benar. Adapun Metode pengembangan sistem model Prototype dapat dilihat pada Gambar 1.

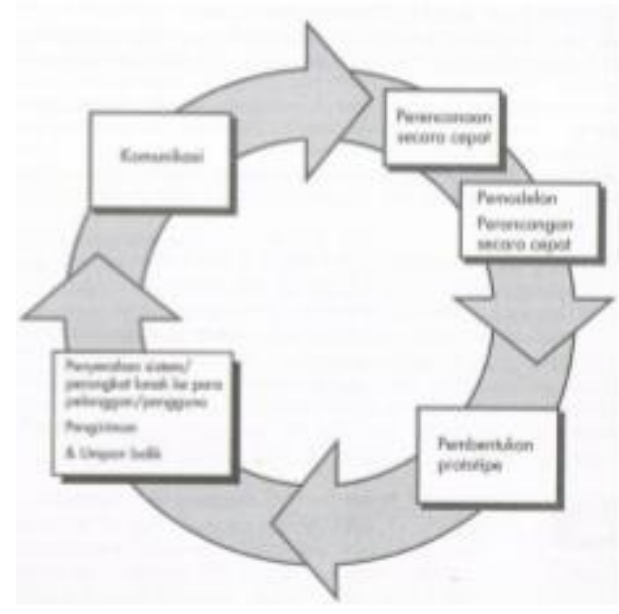

Gambar 1. Prototype Model

Berikut adalah tahapan dalam metode prototype :

1. Komunikasi, yaitu analisis terhadap kebutuhan pengguna. Penulis dan klien bertemu dan menentukan tujuan umum, kebutuhan yang diketahui dan gambaran bagian-bagian yang akan dibutuhkan berikutnya dalam membangun sistem.

2. Perencanaan secara cepat yaitu pembuatan desain secara umum untuk selanjutnya dikembangkan kembali.

3. Pembentukan prototype, yaitu pembuatan perangkat prototype termasuk pengujian dan penyempurnaan.

4. Evaluasi terhadap prototype, yaitu mengevaluasi prototype dan memperhalus analisis terhadap kebutuhan pengguna.

5. Perbaikan prototype, yaitu pembuatan tipe yang sebenarnya berdasarkan hasil dari evaluasi prototype.

6. Produksi akhir, yaitu memproduksi perangkat secara benar sehingga dapat digunakan oleh pengguna.

\section{E. PHP (PHP Hypertext Preprocessor)}

Menurut Paranginangin (2006:2), PHP singkatan dari PHP Hypertext Preprocessor yang digunakan sebagai bahasa script serverside dalam pengembangan web yang disisipkan pada dokumen HTML.

\section{F. MY SQL}

Menurut Rosa dan Shalahuddin (2013:46), SQL (Structured Query Language) adalah bahasa yang digunakan untuk mengolah data 
pada RDBMS (Relational Database Management System).

\section{G. Web}

Menurut Supriyanto (2007), "Web adalah Jenis layanan koleksi keterhubungan dengan dokumen dokumen yang di simpan di internet dan diakses menggunakan protocol (HTTP) HyperText Transfer Protocol yang akan menghasilkan fasilitas informasi atau dokumen yang dapat diakses, dapat berupa data,

teks, gambar, suara, video dengan di perlukan web browser internet untuk menulis alamat di Internet Explorer, Netscape, Opera, Mozila Firefox, dan Google Chome".

\section{H. Xampp}

Adalah web server yang mudah digunakan untuk menampilkan halaman web yang dinamis

\section{Pengujian Black Box}

Menurut Rosa dan Salahuddin (2013:275), Pengujian black-box dilakukan dengan membuat kasus uji yang bersifat mencoba semua fungsi dengan memakai perangkat lunak apakah sesuai dengan spesifikasi yang dibutuhkan. Kasus uji yang dibuat dengan kasus benar dan kasus salah, misalkan untuk kasus login maka kasus uji yang dibuat adalah:

1. Jika pengguna memasukkan nama pengguna (username) dan kata sandi (password) yang benar;

2. Jika pengguna memasukkan nama pengguna (username) dan kata sandi (password) yang salah, misalnya nama pengguna benar tetapi kata sandi salah atau sebaliknya atau keduanya salah.

\section{METODE PENELITIAN}

\section{A. Tahapan Penelitian}

Tahapan penelitian merupakan gambaran jalannya penelitian, sehingga dari tahapan ini nantinya akan tergambar jelas apa yang akan dilakukan dalam penelitian ini. Adapun tahapan penelitian tersebut dapat dilihat pada Gambar dibawah ini .

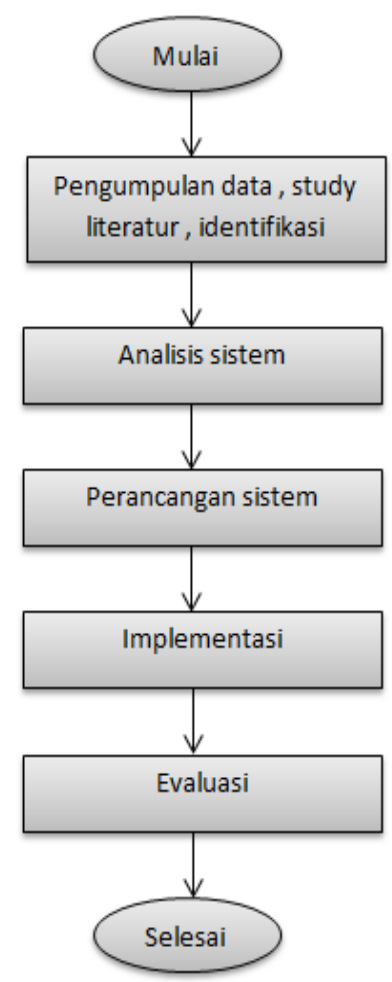

Gambar 2 Alur Metode Penelitian

\section{B. Use Case Diagram}

Use case diagram sistem informasi pemasangan listrik baru berbasis web barcode .

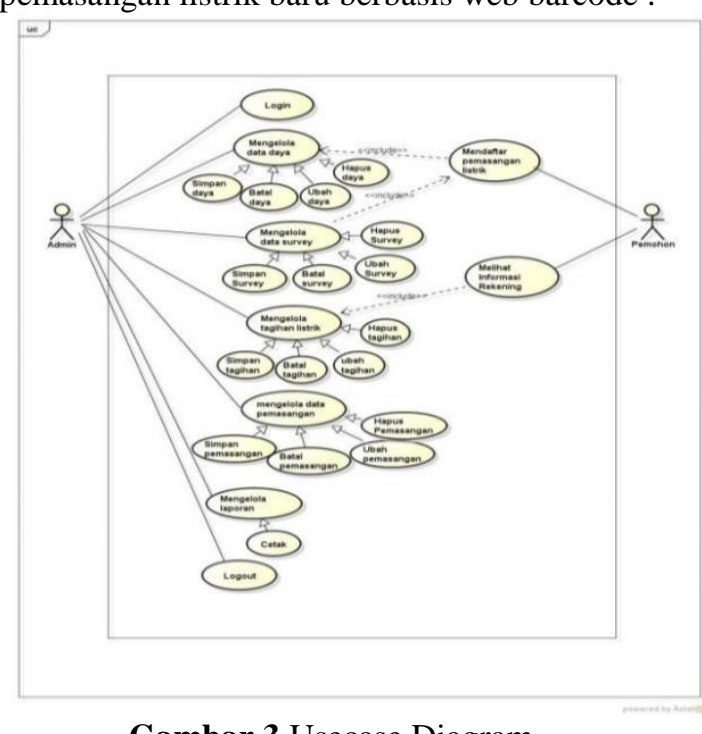

Gambar 3 Usecase Diagram

\section{Class Diagram}

Diagram Kelas atau Class Diagram menggambarkan struktur sistem dari segi pedefinisian kelas-kelas yang akan dibuat 
untuk membangun sistem. Clas Diagram tersebut dapat dilihat pada Gambar 4.

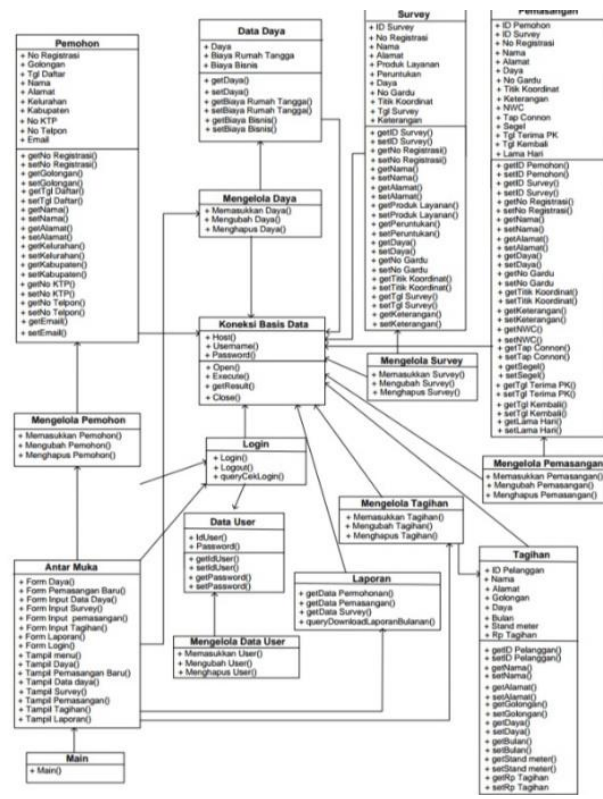

Gambar 4 Class Diagram

\section{Activity Diagram}

Activity diagram pada sistem informasi pemasangan ini menggambarkan workflow (aliran kerja) atau aktivitas dari sebuah sistem tersebut dan menggambarkan aktivitas apa yang dapat dilakukan oleh sistem informasi pemasangan listrik baru pada PT rahayu. Adapun Activity Admin dan Pemohon dapat dilihat pada gambar dibawah ini .

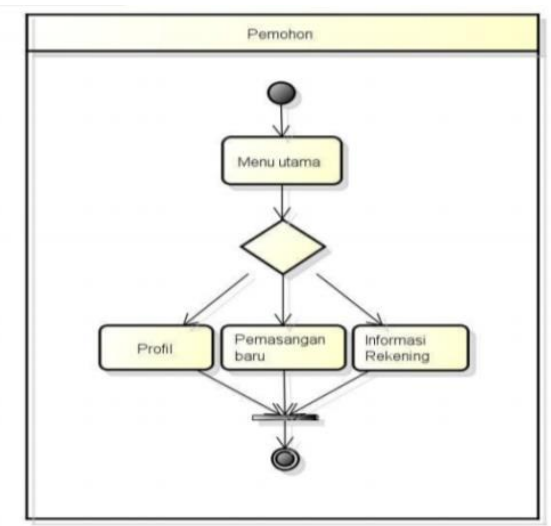

Gambar 5 Activity Diagram

\section{HASIL DAN PEMBAHASAN}

\section{A. Form Menu Utama}

Form menu utama merupakan tampilan pertama pada saat program dijalankan. Form menu utama ini, berfungsi untuk mengakses menu-menu lainnya yang terdapat pada program. Adapun Form Menu Utama bisa dilihat pada gambar dibawah ini .

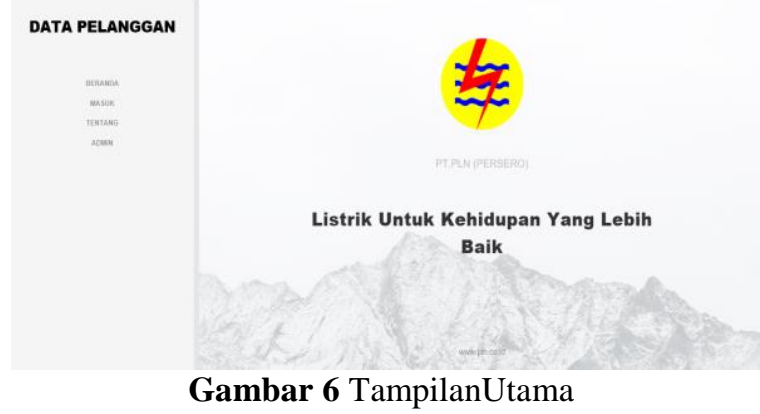

B. Form Login

Form login merupakan tampilan awal untuk masuk ke dalam sistem informasi pemasangan listrik baru tetapi hanya untuk hak akses bagian perusahaan atau admin yang bisa masuk dengan cara menginputkan username dan password dengan kata admin selain admin aplikasi ini tidak bisa dijalankan oleh seseorang yang tidak berhak menggunakannya.

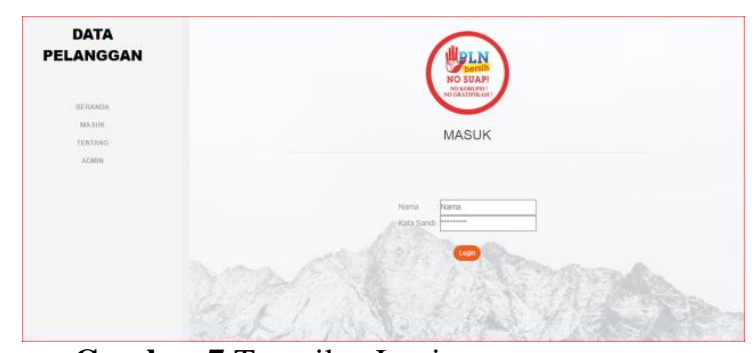

Gambar 7 Tampilan Login

\section{Form Admin}

Form admin merupakan form yang mengelola sistem tersebut

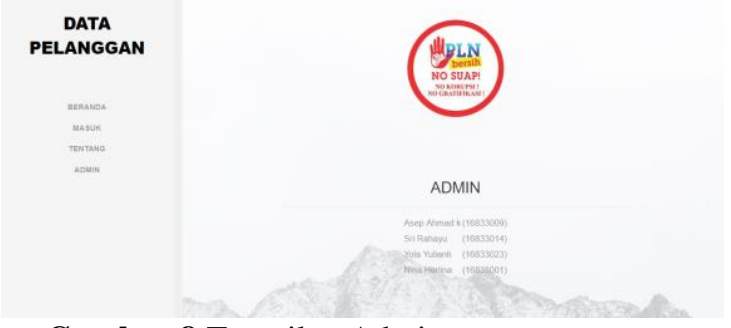

Gambar 8 Tampilan Admin

\section{Form Tentang}

Form tentang merupakan form tentang sistem pemasangan baru listrik berbasis web barcode. 


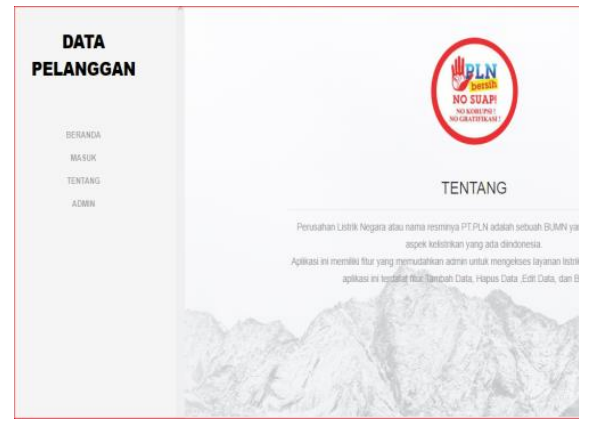

Gambar 9 Tampilan Tentang

\section{E. Form pendaftaran}

Form pendaftaran merupakan tampilan setelah login, form ini berfungsi untuk menginputkan data pertama kali sebelum masuk dalam daftar pelanggan .

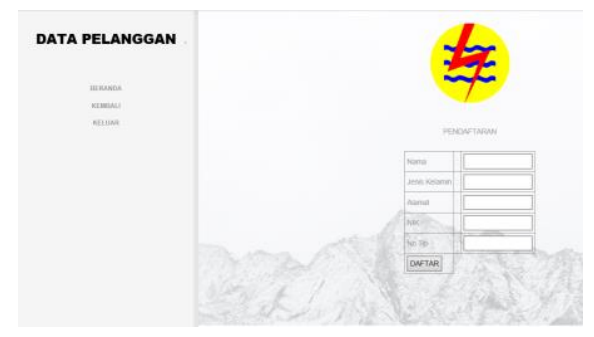

Gambar 10 Tampilan Pendaftaran

\section{F. Form Menu Tambah}

Form menu tambah ini merupakan tampilan yang bisa disebut juga form pendaftaran ke dua setelah pendaftaran awal yang hanya menginputkan nama dan lain-lain. Kalau di form ini pemohon yang ingin pasang baru listrik dikantor pln yang nantinya akan diinput otomatis ke database dan tersimpan didalam sistem dengan memilih daya dan diinputkan no token nya.

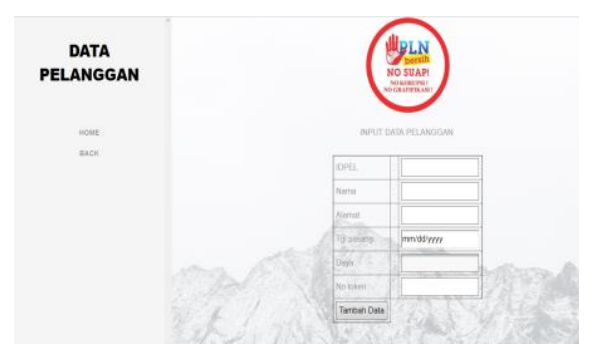

Gambar 11 Tampilan Pendaftaran

\section{G. Form Menu Edit}

Form menu edit berfungsi untuk merubah data didalam tabel .

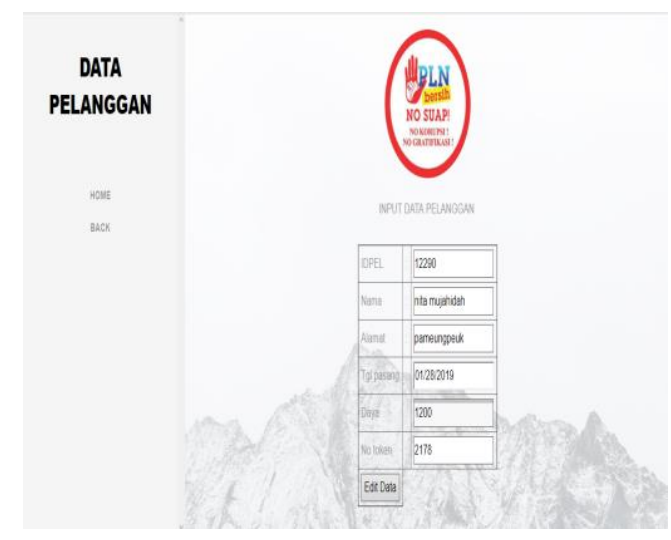

Gambar 12 Tampilan Edit

\section{H. Form Menu Barcode}

Form menu barcode berfungsi untuk mencetak sebuah barcode id_pelanggan dan nama nya secara otomatis

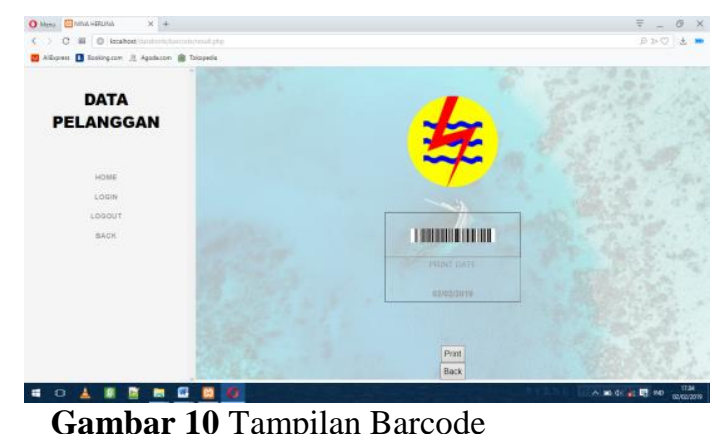

\section{Kesimpulan}

Sistem informasi pemasangan baru listrik berbasis web barcode ini dapat membantu antrian pemohon saat melakukan pendaftaran baru listrik serta membantu mengelola data pemasangan baru listrik agar tidak terjadi penumpukan data dan kesulitan pada saat pencarian data.

\section{Daftar Pustaka}

[1] Abidin, M. Z., \& Rachmansyah. (2014). Perancangan

[2] Al Fattah, hanif. 2007. Analisis \& Perancangan Sistem Informasi. Yogyakarta: Andi. 
[3] Nurdiana, Dian, and Andri Suryadi. "PERANCANGAN BUDAYAKU MENGGUNAKAN INDONESIAKU GAME MDLC." JURNAL PETIK 3.2 (2017) 39-44.

[4] Dina, A. P., Fatoni, \& Yulianingsih, E. (2014). Sistem Pendaftaran Pasang Baru Secara Online Pada PT PLN (Persero) WS2JB Rayon Ampera Palembang. Jurnal Bina Darma Vol.1 N0. 01, 110.

[5] Sistem Informasi Layanan Pelanggan PLN Berbasis Website Pada PLN Rayon Ampera. Jurnal STMIK MDP Vol.1 No.01, 1-10.

[6] Suryadi, Andri. "PERANCANGAN APLIKASI GAME EDUKASI MENGGUNAKAN MODEL WATERFALL." JURNAL PETIK 3.1 (2017): 8-13.

[7] Suryadi, Andri. "SISTEM REKOMENDASI PENERIMAAN MAHASISWA BARU MENGGUNAKAN NAIVE BAYES CLASSIFIER DI INSTITUT PENDIDIKAN INDONESIA." Joutica 3.2 (2018): 171182.

[8] Suryadi, Andri. "SISTEM INFORMASI LEMBAGA PEMASYARAKATAN Studi Kasus: Lembaga Pemasyarakatan Kelas IIB Kota Garut." JURNAL PETIK4.2 (2018): 120-127.

[9] Suryadi, Andri, Dian Nurdiana, and IImu Pendidikan Garut. "Sistem Pendukung Keputusan Seleksi Ujian Masuk Perguruan Tinggi Menggunakan NBC (Naive Bayes Classifier)." Kinetik 1.3 (2016): 173 182.

[10] Suryadi, Andri, and Dian Nurdiana. "Sistem Pengambilan Keputusan Untuk Pemilihan Teknisi Lab Dengan Multi Kriteria Menggunakan Metode AHP (Analytic Hierarchy Process)." Mosharafa: Jurnal Pendidikan Matematika 4.1 (2015): 11-21.

[11] Suryadi, Andri, Erwin Harahap, and Adi Rachmanto. "RANCANG BANGUN SISTEM INFORMASI PERSEDIAAN OBAT BERBASIS WEB DI APOTEK XYZ." JURNAL PETIK4.2 (2018): 114-119.
[12] Sutabri, Tata. 2012. Analisa Sistem Informasi. Yogyakarta: Andi. Tjahjono, B. 2008. Analisis Dan Perancangan Sistem Informasi Pemasangan Jaringan Listrik Baru Pada PT PLN (Persero) Area Pelayanan Sepatan. Jurnal Fasilkom Vol.6 No.2, 117-125. 